\title{
A global initiative to improve the care of underserved people with spinal disorders deserves support
}

\author{
Robert Gunzburg ${ }^{1} \cdot$ Marek Szpalski $^{2}$
}

Received: 10 August 2018 / Accepted: 13 August 2018 / Published online: 27 August 2018

c) Springer-Verlag GmbH Germany, part of Springer Nature 2018

The Global Spine Care Initiative (GSCI) was convened by World Spine Care (WSC), a charity, founded by Joan and Scott Haldeman in 2008. With the support of an international team of dedicated like-minded clinicians and researchers, WSC has established spine care programs in four underserved communities in low- and middle-income countries. Over 50 volunteers have donated their time and expertise from 6 weeks to 1 year providing care and establishing public education programs for people who have minimal or no access to spine care. The mission of WSC is "to improve lives in underserved communities through sustainable, integrated, evidence-based, spine care".

In order to achieve this goal, WSC convened the Global Spine Care Initiative. The principle investigators of the GSCI included Scott Haldeman, Margareta Nordin, Roger Chou, Pierre Côté and Eric Hurwitz. These investigators assembled a worldwide multidisciplinary team from all continents (except Antarctica) to review the literature on spine care from low- and middle-income countries and beyond. This was followed by a consensus process that included 68 spine care researchers and clinicians from 24 countries. The proceedings of the GSCI are now published as a focus issue of the European Spine Journal as 15 articles. Eight of the articles are literature reviews to determine the extent of the problem and which evidence-based interventions should reasonably be included in an evidence-based spine care pathway. There are five consensus papers to develop an implementable model of care. The report of the GSCI includes a methodology paper outlining qualifications, potential biases and conflicts of the participants and an executive summary.

Robert Gunzburg

robert@gunzburg.be

1 Cavell Spine Centre, Edith Cavell Clinic, Edith Cavell Street 32, 1180 Brussels, Belgium

2 Department of Orthopedics and Trauma Surgery, Iris South Teaching Hospitals, Brussels, Belgium
The authors recommend that spine care should include community-based and self-care, primary spine care, secondary spine care and tertiary spine care and focus on the prevention of all forms of spinal disorders and the reduction in spine-related disability. The authors developed a new classification of spinal disorders, a care pathway for all patients who would present to a spine clinic, a description of the resources necessary to implement a spine management program and the steps necessary to implement a model of care that includes a prevention strategy for disability.

The European Spine Journal (ESJ) Editorial Board was very interested to promote and distribute this knowledge to clinicians, politicians, providers, insurance companies and others in low- and middle-income countries. The ESJ recognized that WSC is a charity and has limited resources and therefore agreed to reduce the cost of the publication after discussion with its publishing company, Springer. ESJ was also able to provide a discount for open-access publication of four consensus articles and the Executive Summary so that these articles could be easily accessed by policy makers and clinicians in low- and middle-income communities. The ESJ Editorial Board agrees that the development of a model of spine care that can be implemented and easily translated and taught is important in low- and middle-income countries if there is any possibility of reducing the impact of spinerelated disability.

The GSCI articles represent work that took almost 4 years to complete and required multiple revisions to be acceptable to the diffuse panel that made up the GSCI, to ensure that the articles were based on the evidence and were clear enough to allow for easy comprehension by readers. Spinal disorders and especially low back and neck pain are the most prevalent disorders leading to disability globally and are recognized by the WHO as the number 1 non-communicable disease in the world. This is true for low- and middle-income countries, but also true for high-income countries when expressed as DALYs. This fact was supported at the last WHO World Health Assembly in May 2018 when the WHO created the 
Global Rehabilitation Alliance. WSC is one of the founding members of this alliance.

The ESJ is committed to advancing evidence-based spine care in LMICs. To this end, a number of members of the ESJ Editorial Board participated, as speakers, at the WSC Third Botswana Spine Care Conference on "Creating a country wide program for the prevention of spine disability" held in Gaborone Botswana in May 2018. In addition, the ESJ Editorial Board agreed to be a sponsor for this conference where more than 300 participants from sub-Sahara countries attended the presentations.

ESJ is committed to promoting evidence-based care throughout the world and is proud to have collaborated with the international and interdisciplinary GSCI participants to advance best evidence spine care. The ESJ hopes that this initiative will lead to further academic discussion on how to improve care for spinal disorders in LMICs and encourages further studies addressing this. It is needed.

\section{Compliance with ethical standards}

Conflict of interest The authors declare that they have no conflict of interest. 